\title{
The Effects of Remote Ischemic Preconditioning and N-Acetylcysteine with Remote Ischemic Preconditioning in Rat Hepatic Ischemia Reperfusion Injury Model
}

\author{
Ali Ihsan Uysal, ${ }^{1}$ Elvan Ocmen, ${ }^{1}$ Mert Akan, ${ }^{1}$ Sevda Ozkardesler, ${ }^{1}$ Bekir Ugur Ergur, \\ Ensari Guneli, ${ }^{3}$ Tuncay Kume, ${ }^{4}$ Uğur Koca, ${ }^{1}$ and Belgin Unal Togrul ${ }^{5}$ \\ ${ }^{1}$ Department of Anesthesiology and Reanimation, Dokuz Eylul University Medical School, Inciralti, 35340 Izmir, Turkey \\ ${ }^{2}$ Department of Histology and Embryology, University Medical School, 35340 Izmir, Turkey \\ ${ }^{3}$ Department of Laboratory Animal Science, University Medical School, 35340 Izmir, Turkey \\ ${ }^{4}$ Department of Biochemistry, University Medical School, 35340 Izmir, Turkey \\ ${ }^{5}$ Department of Public Health, University Medical School, 35340 Izmir, Turkey
}

Correspondence should be addressed to Elvan Ocmen; elvan.sahin@gmail.com

Received 27 August 2013; Accepted 22 November 2013; Published 8 January 2014

Academic Editor: Ahmet Eroglu

Copyright (C) 2014 Ali Ihsan Uysal et al. This is an open access article distributed under the Creative Commons Attribution License, which permits unrestricted use, distribution, and reproduction in any medium, provided the original work is properly cited.

\begin{abstract}
Background. Remote ischemic preconditioning (RIP) and pharmacological preconditioning are the effective methods that can be used to prevent ischemia reperfusion (IR) injury. The aim of this study was to evaluate the effects of RIP and N-Acetylcysteine (NAC) with RIP in the rat hepatic IR injury model. Materials and Methods. 28 rats were divided into 4 groups. Group I (sham): only laparotomy was performed. Group II (IR): following 30 minutes of hepatic pedicle occlusion, 4 hours of reperfusion was performed. Group III (RIP + IR): following 3 cycles of RIP, hepatic IR was performed. Group IV (RIP + NAC + IR): following RIP and intraperitoneal administration of NAC $(150 \mathrm{mg} / \mathrm{kg})$, hepatic IR was performed. All the rats were sacrificed after blood samples were taken for the measurements of aspartate aminotransferase (AST) and alanine aminotransferase (ALT) levels and liver was processed for conventional histopathology. Results. The hepatic histopathological injury scores of RIP + IR and RIP + NAC + IR groups were significantly lower than IR group $(P=0.006, P=0.003$, resp.). There were no significant differences in AST and ALT values between the IR, RIP + IR, and RIP + NAC + IR groups. Conclusions. In the present study, it was demonstrated histopathologically that RIP and RIP + NAC decreased hepatic IR injury significantly.
\end{abstract}

\section{Introduction}

Liver ischemia/reperfusion injury (IRI) may occur during surgery, like hepatectomy or transplantation, or systemic hypoxia, like respiratory or circulatory failure. Reperfusion can cause more damage than ischemia itself [1]. During ischemia toxic oxygen radicals are produced in the tissues. These oxygen and superoxide radicals can cause endothelial injury, an increase in microvascular permeability and tissue edema in the reperfusion period $[2,3]$. Besides activated adhesion molecules and cytokines can start systemic inflammatory response, which are known as IRI [3]. Although tissue ischemia is the main starter of the pathophysiological changes, reperfusion causes inflammation [4].
Liver IRI can cause hepatic failure especially in the presence of coexisting hepatic disease [5] or even multiple organ failure [6-8].

Ischemic preconditioning (IP) is one of the most common techniques that are used to reduce hepatic IRI [9]. After a short period of ischemia/reperfusion, prolonged ischemia reperfusion (IR) causes less injury in the tissue, which is called direct IP [10]. Similarly, brief ischemia/reperfusion stimulus to an organ can protect a remote organ against IRI and this is called remote ischemic preconditioning (RIP) [11]. Pharmacological method is another way to protect the tissue from IRI and many different drugs were studied for this purpose $[9,12]$. N-Acetylcysteine (NAC) is one of the most commonly used drugs in several IRI studies [13-17]. 
The aim of this study is to compare the effectiveness of RIP and NAC addition to RIP in the rat hepatic IRI model.

\section{Material and Methods}

After approval of the Experimental Animal Research Committee of our institution, the study was conducted at the experimental animals' laboratory of our institute. Twentyeight adult male Wistar albino rats weighing 250-300 g were used in this study.

Rats were randomized into four groups: Group I (sham, $n=7)$ : following laparotomy, at the 65th minute of the anesthesia hepatic pedicle dissection was performed and waited till the 270th minute of the anesthesia without any procedure. Group II (IR, $n=7$ ): At the 65th minute of the anesthesia, total hepatic ischemia for 30 minutes and four hours of reperfusion were performed. Group III (RIP + IR, $n=7$ ): following laparotomy, three cycles of RIP applied to left hind limb were performed 5 minutes before hepatic IR. Group IV (RIP + NAC + IR, $n=7): 150 \mathrm{mg} / \mathrm{kg}$ NAC (Asist amp $300 \mathrm{mg} / 3 \mathrm{~mL}$ amp, Hüsnü Arsan Ilaç Sanayi, Turkey) was administered intraperitoneally at the 60th minute of the anesthesia in addition to the procedures of group III.

2.1. Experimental Protocol. Rats were anesthetized with intraperitoneal $50 \mathrm{mg} / \mathrm{kg}$ ketamine (Ketalar flk., Pfizer Pharma $\mathrm{GMBH}$, Germany) and $10 \mathrm{mg} / \mathrm{kg}$ xylazine hydrochloride (Alfazyne \% 2, Alfasan International, Holland). Anesthesia was maintained with intraperitoneal $25 \mathrm{mg} / \mathrm{kg}$ ketamine when needed. Durations of anesthesia were equal in all groups.

Laparotomy was performed with a midline incision. After the liver and the hepatic pedicle were visualized a microvascular clamp was used for performing ischemia. Successful occlusion of the pedicle was confirmed by the change of the color of the liver. Rats were heated with a heating lamp during the operation to maintain a rectal body temperature of $37-37.5^{\circ} \mathrm{C}$. Hydration was maintained with subcutaneous infusion of $3 \mathrm{~mL} / \mathrm{kg} / \mathrm{h}$ saline solution.

The effectiveness of the RIP method that we used has been shown previously $[18,19]$. For this purpose an elastic bandage $(1 \mathrm{~cm}$ width and $30 \mathrm{~cm}$ length) to the proximal left hind limb was wrapped circularly 3 times and squeezed. Three cycles of 10-minute ischemia and 10-minute reperfusion were performed.

At the end of the study, sternotomy was performed under anesthesia to all rats and blood samples were taken from the right atrium. Then hepatectomy was performed for histopathology and rats were sacrificed by exsanguination. Liver samples were fixed for 24-48 hours in 10\% buffered formaldehyde and examined by a light microscope.

Congestion, necrosis, cytoplasmic vacuolization, cytoplasmic hypereosinophilia, nuclear pyknosis, and inflammatory cell number were examined to assess the degree of the liver injury. Hepatic histopathological injury score (HHIS) [20] was classified according to the severity of the injury (grade 0: minimal or no injury; grade 1: mild injury; grade 2: moderate injury; grade 3: severe injury).
Blood samples were centrifuged for 10 minutes at $3000 \mathrm{rpm}$ and plasma samples were stored at $-20^{\circ} \mathrm{C}$ until the measurement. Cobas Integra 800, Roche, USA, analyzer was used for the measurements of Aspartate aminotransferase (AST) and alanine aminotransferase (ALT) levels.

For statistical analysis, SPSS 15.0 (Statistical Package for the Social Sciences version 15, Chicago, IL, USA) was used. Kruskal-Wallis variance analysis was performed to analyze the data. All data were expressed as mean \pm standard deviation (mean $\pm \mathrm{SD}$ ) using Mann-Whitney $U$ test for pair wise comparisons of groups. The level of statistical significance was accepted as $P<0.05$.

\section{Results}

A total of 28 rats were included in the study. None of the rats died during the study period.

3.1. Hepatic Histopathological Injury Scores. The HHIS of the sham operated group was significantly lower than the IR, RIP $+\mathrm{IR}$, and RIP + NAC + IR groups (resp., $P=0.001, P=$ $0.001, P=0.002)$. The scores were significantly higher in the IR group than in the RIP + IR, and RIP + NAC + IR groups (resp., $P=0.006, P=0.003$ ). The difference between the scores of the RIP + IR and RIP + NAC + IR groups was not significant $(P=0.334)$ (Table 1$)$.

In the sham group, normal morphological features were observed. Overall injury grade was 0 (Figures 1(a), 1(b), 1(c), and $1(\mathrm{~d})$ ).

In the IR group, disintegration and hemorrhage in the hepatic chords, sinusoidal dilatation, and mononuclear cell infiltration was observed. In some regions focal necrosis were also detected (Figures 2(a), 2(b), 2(c), and 2(d)).

In the RIP + IR group, integration of the hepatic chords was better and less sinusoidal dilatation, mononuclear cell infiltration, and degeneration of hepatic cells were observed compared to the IR group (Figures 3(a), 3(b), and 3(c)).

In the RIP + NAC + IR group histopathological findings were similar to the RIP + IR group. Although no significant difference was observed, HHIS was lower than the RIP + IR group (Figures 4(a), 4(b), and 4(c)).

3.2. Biochemical Parameters. The values of AST and ALT for the IR (resp., $P=0.018, P=0.018$ ), RIP + IR (resp., $P=$ $0.0003, P=0.003$ ), and RIP + NAC + IR (resp., $P=0.002$, $P=0.002)$ groups were significantly higher than the sham group (Table 1). No statistically significant differences were determined for the values of AST and ALT in comparisons between the IR group and RIP + IR group (resp., $P=0.886$, $P=0.086)$ and between the IR group and RIP + NAC + IR group (resp., $P=0.406, P=0.064$ ). Also there were no significant differences between the AST and ALT values of the RIP + IR and RIP + NAC + IR groups (resp., $P=0.775$, $P=0.475)$.

\section{Discussion}

In the present study, it was demonstrated histopathologically that RIP and RIP + NAC decreased hepatic IR injury significantly. Although HHIS was better in the RIP + NAC 


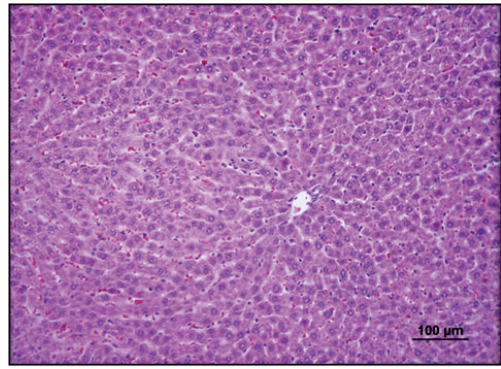

(a)

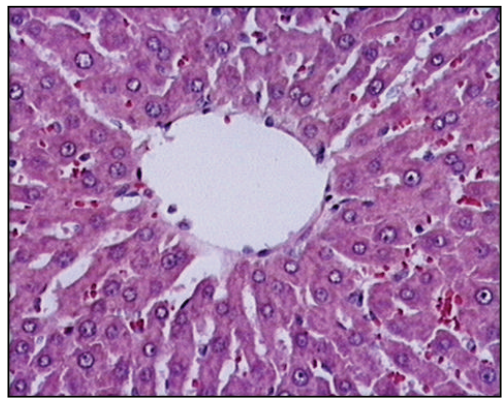

(c)

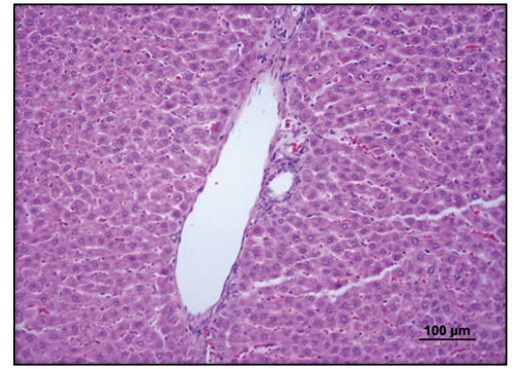

(b)

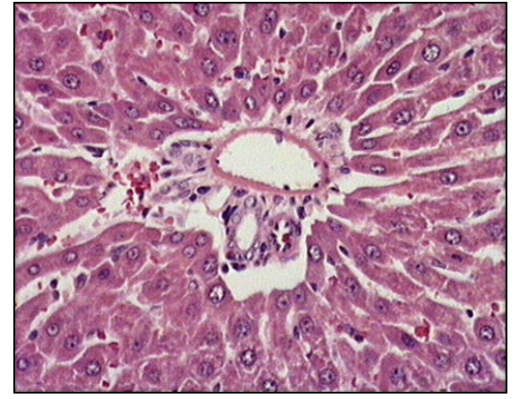

(d)

FIGURE 1: The liver sections of sham group $(\times 20$ and $\times 40)$. ((a) and $(c))$ normal sight of vena centralis and ((b) and (d)) normal sight of portal region.

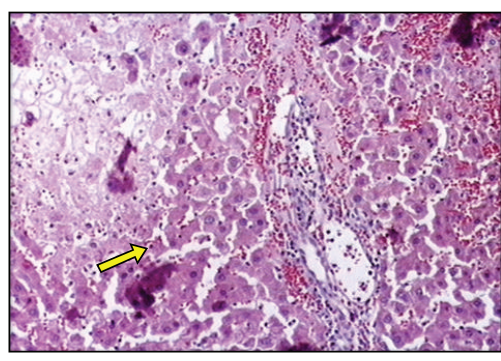

(a)

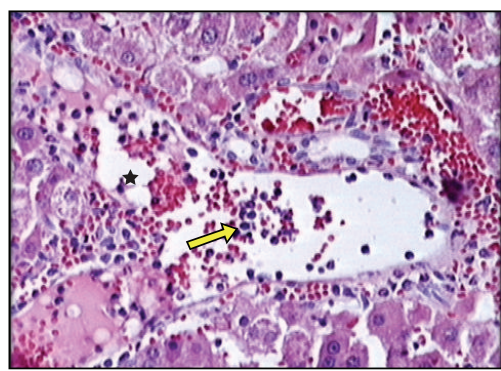

(c)

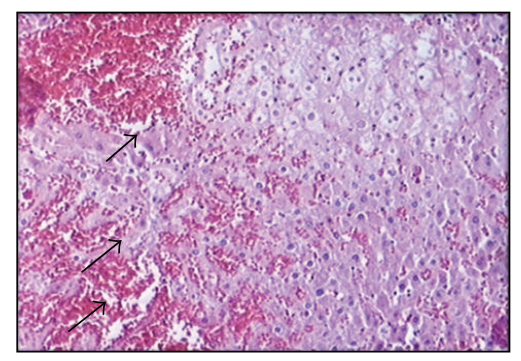

(b)

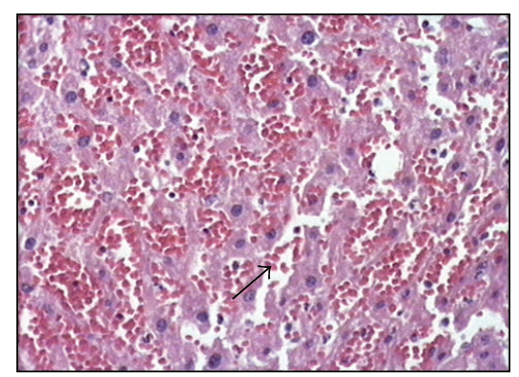

(d)

FIGURE 2: The liver sections of ischemia reperfusion group $(\times 20$ and $\times 40)$. ((a) and (c)) The integrity of hepatocyte cell cords is destroyed, sinusoidal dilatation, mononuclear cell infiltration (star), and focal necrosis of the hepatocytes (yellow arrows) ((b) and (d)). Erythrocyte extravasation (black arrows). 
TABLE 1: Aspartate aminotransferase, alanine aminotransferase, and hepatic histopathological injury score values for the study groups.

\begin{tabular}{lccc}
\hline & AST (U/L) & ALT (U/L) & HHIS \\
\hline Sham group & $138.4 \pm 30.0$ & $50.0 \pm 9.7$ & $0.00 \pm 0.00$ \\
IR group & $1034.7 \pm 521.0^{*}$ & $834.2 \pm 427.6^{*}$ & $2.28 \pm 0.48^{*}$ \\
RIP + IR group & $1081.8 \pm 227.5^{*}$ & $1203.6 \pm 297.8^{*}$ & $1.28 \pm 0.48^{* \#}$ \\
RIP + NAC + IR group & $1703.8 \pm 1145.3^{*}$ & $1237.4 \pm 540.5^{*}$ & $1.00 \pm 0.57^{* \#}$ \\
\hline
\end{tabular}

${ }^{*} P<0.05$, compared to sham group.

${ }^{\#} P<0.05$, compared to IR group.

AST: aspartate aminotransferase, ALT: alanine aminotransferase, HHIS: hepatic histopathological injury score, IR: ischemia-reperfusion, RIP: remote ischemic preconditioning, NAC: N-Acetylcysteine.

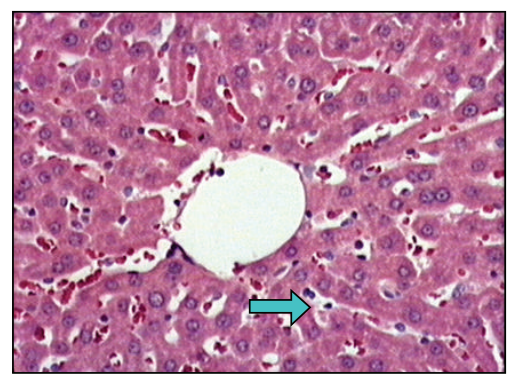

(a)

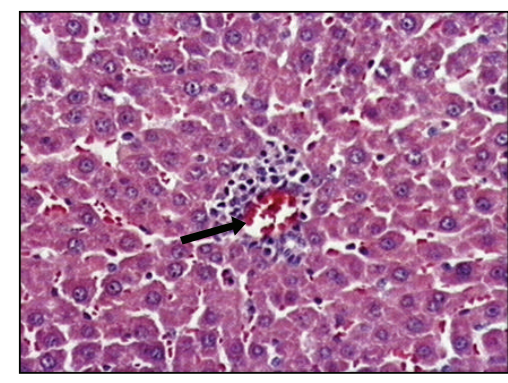

(b)

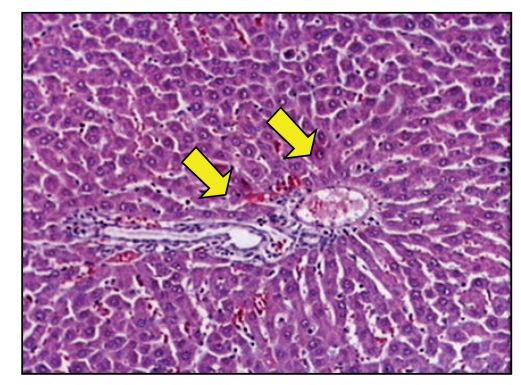

(c)

FIGURE 3: The liver sections of remote ischemic preconditioning + ischemia reperfusion group $(\times 20$ and $\times 40)$. (a) Blue arrow is showing the integrity of hepatocyte cell cords is more regular and less sinusoidal dilatation compared to ischemia reperfusion group. (b) Black arrow shows less focal necrosis. (c) Yellow arrows point the portal region which is close to normal.

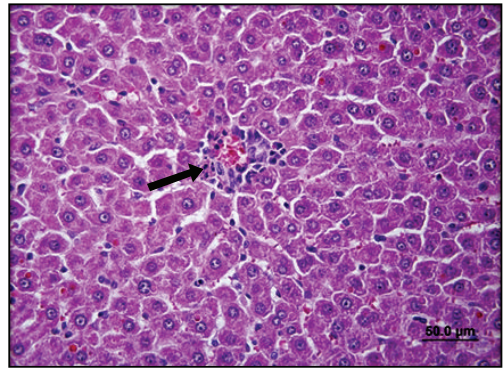

(a)

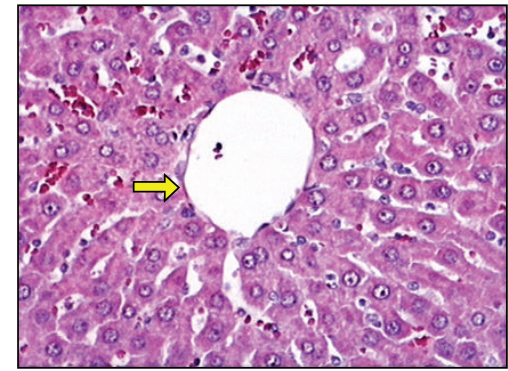

(b)

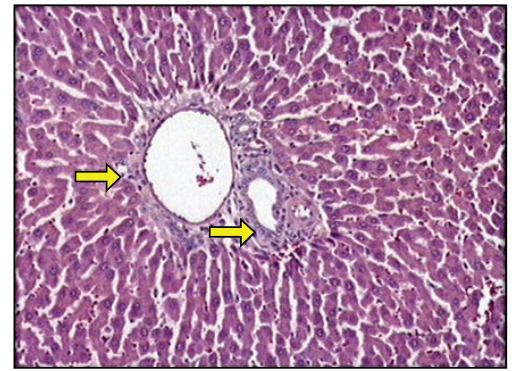

(c)

FIGURE 4: The liver sections of remote ischemic preconditioning + N-Acetylcysteine + ischemia reperfusion group $(\times 20$ and $\times 40)$. (a) Focal necrosis of the hepatocytes has been seen rarely (black arrow). ((b) and (c)) Less sinusoidal dilatation compared to ischemia reperfusion group and yellow arrows point the portal region which is close to normal.

group, there was no significant difference between RIP + IR and RIP + NAC + IR groups. According to the biochemical parameters, both methods could not prevent IR injury.

Ischemia/reperfusion injury induces cholestasis and reduces bile secretion temporarily. The changes of the bile flow result with an increase in AST/ALT levels, liver myeloperoxidase (MPO) activity, and plasma bilirubin levels and return to normal in 1-3 days [21]. The best indicators of hepatic IRI are enzyme activities like plasma AST, ALT, and histopathologic changes $[6,22]$. Therefore we choose AST, ALT, and HHIS for detecting IRI.

Total [23] or partial [7] hepatic ischemia models can be used for hepatic IR studies. Partial ischemia causes less mesenteric congestion but besides its technical difficulty this model does not reflect the clinical practice. The total ischemia time that hepatic IRI can occur but does not impair the hemodynamic stability was determined as at least 25 minutes [19, 23]. In this study, 30 minutes of total hepatic ischemia was used because of the similarity to the clinical practice (Pringle manoeuvre).

In the present study hepatic IRI has been shown after 30 minutes of total hepatic ischemia with both biochemical and histopathological methods. Histopathological and biochemical changes in the IR group compared to the sham operated group indicated that hepatic IR model was applied correctly.

Remote IP was first described by Przyklenk et al. [24] who showed that brief occlusion of coroner arteries protects the heart against prolonged ischemia. The protective effect of 
RIP was also shown in lung [7], kidney [25], muscle [26], and bowel [27] IRI. RIP was suggested to be an effective and easy method for protecting the liver against IRI without generating a direct trauma to the liver [23, 28]. Lai et al. [28] showed that 4 cycles of IP by clamping the femoral artery before partial ischemia of the liver were effective to reduce the hepatic IRI. Küntscher et al. [18] reported that using a tourniquet would be as effective as direct clamping of the femoral artery for generating RIP. Abu-Amara et al. [29] showed that six cycles of RIP for four minutes before hepatic IR significantly reduced the hepatic IRI. Saita et al. [26] found that the most effective IP method is 10 minutes ischemia and 10 minutes reperfusion for 3 cycles for skeleton muscle IRI. Kanoria et al. [23] demonstrated that 3 cycles of RIP significantly reduce plasma levels of transferases and increase hepatic blood flow and peripheral oxygen saturation in a total hepatic ischemia model. Similarly, Şahin et al. [19] reported that 3 cycles of 10 minutes hind limb RIP protect liver from IRI biochemically and histopathologically. In the present study, 3 cycles of hind limb RIP, whose effectiveness was shown, were used but the protective effect of RIP could only be detected histopathologically.

$\mathrm{N}$-Acetylcysteine participates in the glutathione syntheses in the lung and liver as a cysteine source and increases glutathione syntheses and it also bounds free oxygen radicals and protects the cell by preventing cell injury [9]. The hypothesis of this study was combination of RIP and NAC would provide a better tissue protection. This method was chosen because this technique could be easily performed before liver resection or transplantation.

The administration of NAC alone can provide tissue protection [13-17]. In the study of Smyrniotis et al. [16] it was shown that NAC $(0.3 \mathrm{mg} / \mathrm{kg}$ IV) can reduce hepatic IRI biochemically and histopathologically. Galhardo et al. [14] found that $150 \mathrm{mg} / \mathrm{kg}$ IV NAC administration to rats before hepatic ischemia, reduced necrosis, apoptosis, and microvesicular steatosis compared to IR group. But controversial to these findings Ghosh et al. [30] and Baumann et al. [31] could not show the beneficial effects of $150 \mathrm{mg} / \mathrm{kg}$ IV NAC before hepatic ischemia.

In the present study we found that NAC (150 mg/kg IP) combination with RIP before hepatic total ischemia significantly decreased the HHIS compared to IR group. The HHIS of RIP + NAC group was lower than RIP but there was no statistically significant difference between these groups.

We could not confirm the beneficial histological effects of RIP and RIP + NAC with biochemical parameters that show the hepatic functions. Kanoria et al. [32] studied the effects of RIP, 3 cycles of 10 minutes, after 25 minutes of total hepatic ischemia and two hours of reperfusion histologically and biochemically. Unlike our results, they reported a significant reduction in plasma transferase levels and they were compatible with the histological findings. Likewise, Wang et al. [33] detected a significant reduction in ALT levels with RIP after hepatic IR at the first and third hours of reperfusion in mice. But the researchers could not find a significant effect at the second hour of reperfusion. We could not explain the biochemical results that did not confirm our histological findings but the difference of the study animals could be the reason of our varied results. Besides in this study only the early periods of reperfusion are investigated. The possible long-term effects of the drugs could be masked. Therefore newer studies that investigate long-term effects in different animal types are needed.

In conclusion, this study demonstrated that RIP and NAC addition to RIP decreased significantly hepatic IRI histopathologically.

\section{Conflict of Interests}

The authors declare that there is no conflict of interests regarding the publication of this paper.

\section{References}

[1] C. D. Collard and S. Gelman, "Pathophysiology, clinical manifestations, and prevention of ischemia-reperfusion injury," Anesthesiology, vol. 94, no. 6, pp. 1133-1138, 2001.

[2] S.-S. Huang, F.-C. Wei, and L.-M. Hung, "Ischemic preconditioning attenuates postischemic leukocyte-endothelial cell interactions - role of nitric oxide and protein kinase C," Circulation Journal, vol. 70, no. 8, pp. 1070-1075, 2006.

[3] Ç. Olguner, U. Koca, A. Kar et al., "Ischemic preconditioning attenuates the lipid peroxidation and remote lung injury in the rat model of unilateral lower limb ischemia reperfusion," Acta Anaesthesiologica Scandinavica, vol. 50, no. 2, pp. 150-155, 2006.

[4] F. Gueler, J.-K. Park, S. Rong et al., "Statins attenuate ischemiareperfusion injury by inducing heme oxygenase-1 in infiltrating macrophages," American Journal of Pathology, vol. 170, no. 4, pp. 1192-1199, 2007.

[5] P.-A. Clavien, M. Selzner, H. A. Rüdiger et al., "A prospective randomized study in 100 consecutive patients undergoing major liver resection with versus without ischemic preconditioning," Annals of Surgery, vol. 238, no. 6, pp. 843-852, 2003.

[6] D. L. Carden and D. N. Grander, "Pahtophysiology of ischemiareperfusion injury," The Journal of Pathology, vol. 190, pp. 255266, 2000.

[7] C. Peralta, N. Prats, C. Xaus, E. Gelpí, and J. Roselló-Catafau, "Protective effect of liver ischemic preconditioning on liver and lung injury induced by hepatic ischemia-reperfusion in the rat," Hepatology, vol. 30, no. 6, pp. 1481-1489, 1999.

[8] C. Peralta, L. Fernández, J. Panés et al., "Preconditioning protects against systemic disorders associated with hepatic ischemia-reperfusion through blockade of tumor necrosis factor-induced P-selectin up-regulation in the rat," Hepatology, vol. 33, no. 1, pp. 100-113, 2001.

[9] H. Jaeschke and B. L. Woolbright, "Current strategies to minimize hepatic ischemia-reperfusion injury by targeting reactive oxygen species," Transplantation Reviews, vol. 26, no. 2, pp. $103-$ $114,2012$.

[10] J. Laurikka, Z.-K. Wu, P. Iisalo et al., "Regional ischemic preconditioning enhances myocardial performance in off-pump coronary artery bypass grafting," Chest, vol. 121, no. 4, pp. 11831189, 2002.

[11] A. Takaoka, I. Nakae, K. Mitsunami et al., "Renal ischemia/ reperfusion remotely improves myocardial energy metabolism during myocardial ischemia via adenosine receptors in rabbits: effects of 'remote preconditioning," Journal of the American College of Cardiology, vol. 33, no. 2, pp. 556-564, 1999. 
[12] R. Bahde and H.-U. Spiegel, "Hepatic ischaemia-reperfusion injury from bench to bedside," British Journal of Surgery, vol. 97, no. 10, pp. 1461-1475, 2010.

[13] G. Khanna, V. Diwan, M. Singh, N. Singh, and A. S. Jaggi, "Reduction of ischemic, pharmacological and remote preconditioning effects by an antioxidant N-Acetyl Cysteine pretreatment in isolated rat heart," Yakugaku Zasshi, vol. 128, no. 3, pp. 469-477, 2008.

[14] M. A. Galhardo, C. Quireze Jr., P. G. R. Navarro, R. J. Morello, M. D. J. Simões, and E. F. D. S. Montero, "Liver and lung late alterations following hepatic reperfusion associated to ischemic preconditioning or N-acetylcysteine," Microsurgery, vol. 27, no. 4, pp. 295-299, 2007.

[15] J.-C. Orban, J. Levraut, S. Gindre et al., "Effects of acetylcysteine and ischaemic preconditioning on muscular function and postoperative pain after orthopaedic surgery using a pneumatic tourniquet," European Journal of Anaesthesiology, vol. 23, no. 12, pp. 1025-1030, 2006.

[16] V. Smyrniotis, N. Arkadopoulos, G. Kostopanagiotou et al., "Attenuation of ischemic injury by $\mathrm{N}$-acetylcysteine preconditioning of the liver," Journal of Surgical Research, vol. 129, no. 1, pp. 31-37, 2005.

[17] A. O. Sehirli, G. Sener, H. Satiroglu, and G. Ayanoǧlu-Dülger, "Protective effect of N-acetylcysteine on renal ischemia/reperfusion injury in the rat," Journal of Nephrology, vol. 16, no. 1, pp. 75-80, 2003.

[18] M. V. Küntscher, T. Kastell, M. Sauerbier, R. Nobiling, M. M. Gebhard, and G. Germann, "Acute remote ischemic preconditioning on a rat cremasteric muscle flap model," Microsurgery, vol. 22, no. 6, pp. 221-226, 2002.

[19] E. Şahin, Ç. Olguner, H. A. Bodur et al., "Comparison of the effects of the remote and direct ischemic preconditioning in the liver ischemia-reperfusion injury," Turkiye Klinikleri Journal of Medical Sciences, vol. 29, no. 2, pp. 381-387, 2009.

[20] G. Darilmaz, S. Topaloglu, E. Topaloglu et al., "Evaluation of liver damage after application of TVE in the rat model," Transplantation Proceedings, vol. 37, no. 10, pp. 4550-4552, 2005.

[21] V. B. Nieuwenhuijs, M. T. D. Bruijn, R. T. A. Padbury, and G. J. Barritt, "Hepatic ischemia-reperfusion injury: roles of $\mathrm{Ca}^{2+}$ and other intracellular mediators of impaired bile flow and hepatocyte damage," Digestive Diseases and Sciences, vol. 51, no. 6, pp. 1087-1102, 2006.

[22] P.-A. Clavien, S. Yadav, D. Sindram, and R. C. Bentley, "Protective effects of ischemic preconditioning for liver resection performed under inflow occlusion in humans," Annals of Surgery, vol. 232, no. 2, pp. 155-162, 2000.

[23] S. Kanoria, R. Jalan, N. A. Davies, A. M. Seifalian, R. Williams, and B. R. Davidson, "Remote ischaemic preconditioning of the hind limb reduces experimental liver warm ischaemia-reperfusion injury," British Journal of Surgery, vol. 93, no. 6, pp. 762$768,2006$.

[24] K. Przyklenk, B. Bauer, M. Ovize, R. A. Kloner, and P. Whittaker, "Regional ischemic "preconditioning" protects remote virgin myocardium from subsequent sustained coronary occlusion," Circulation, vol. 87, no. 3, pp. 893-899, 1993.

[25] E. Ateş, E. Gency, N. Erkasap et al., "Renal protection by brief liver ischemia in rats," Transplantation, vol. 74, no. 9, pp. 12471251, 2002.
[26] Y. Saita, K. Yokoyama, K. Nakamura, and M. Itoman, "Protective effect of ischaemic preconditioning against ischaemiainduced reperfusion injury of skeletal muscle: how many preconditioning cycles are appropriate?" British Journal of Plastic Surgery, vol. 55, no. 3, pp. 241-245, 2002.

[27] J. M. Davis, D. C. Gute, S. Jones, A. Krsmanovic, and R. J. Korthuis, "Ischemic preconditioning prevents postischemic Pselectin expression in the rat small intestine," American Journal of Physiology: Heart and Circulatory Physiology, vol. 277, no. 6, pp. H2476-H2481, 1999.

[28] I.-R. Lai, K.-J. Chang, C.-F. Chen, and H.-W. Tsai, “Transient limb ischemia induces remote preconditioning in liver among rats: the protective role of heme oxygenase-1," Transplantation, vol. 81, no. 9, pp. 1311-1317, 2006.

[29] M. Abu-Amara, S. Y. Yang, A. Quaglia et al., "Role of endothelial nitric oxide synthase in remote ischemic preconditioning of the mouse liver," Liver Transplantation, vol. 17, no. 5, pp. 610-619, 2011.

[30] S. Ghosh, J. Baumann, B. Falusi, L. Bogár, E. Roth, and J. Gál, "Hemodynamic effects of $\mathrm{N}$-acetylcystein and ischemic preconditioning in a liver ischemia-reperfusion model," Orvosi Hetilap, vol. 149, no. 47, pp. 2245-2249, 2008.

[31] J. Baumann, S. Ghosh, T. Szakmany et al., "Short-term effects of $\mathrm{N}$-acetylcysteine and ischemic preconditioning in a canine model of hepatic ischemia-reperfusion injury," European Surgical Research, vol. 41, no. 2, pp. 226-230, 2008.

[32] S. Kanoria, G. Glantzounis, A. Quaglia et al., "Remote preconditioning improves hepatic oxygenation after ischaemia reperfusion injury," Transplant International, vol. 25, no. 7, pp. 783-791, 2012.

[33] F. Wang, S. E. Birch, R. He et al., "Remote ischemic preconditioning by hindlimb occlusion prevents liver ischemic/reperfusion injury: the role of high mobility group-box 1," Annals of Surgery, vol. 251, no. 2, pp. 292-299, 2010. 


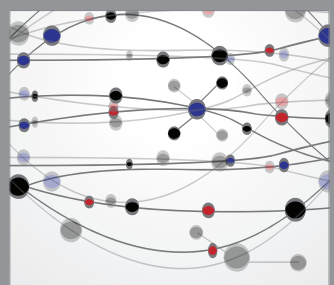

The Scientific World Journal
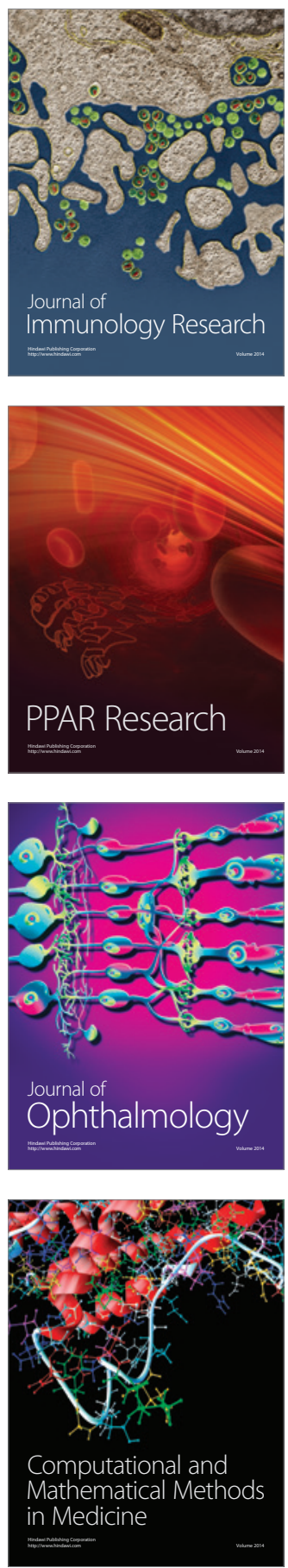

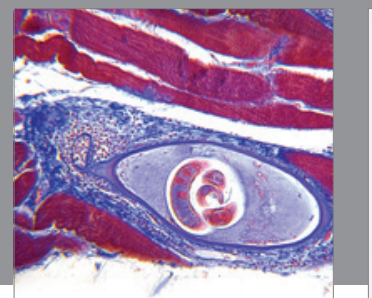

Gastroenterology

Research and Practice
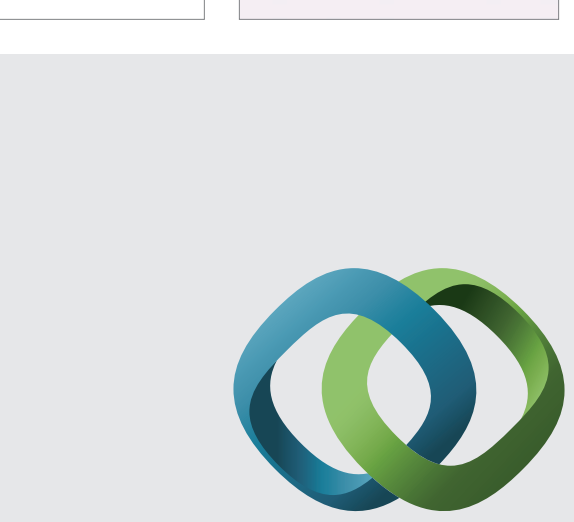

\section{Hindawi}

Submit your manuscripts at

http://www.hindawi.com
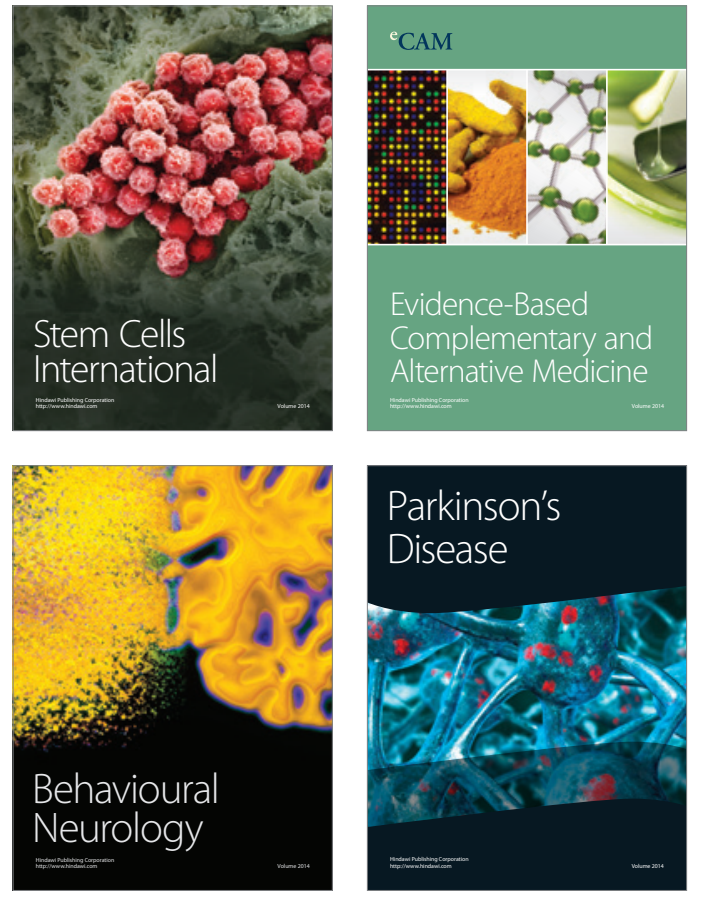
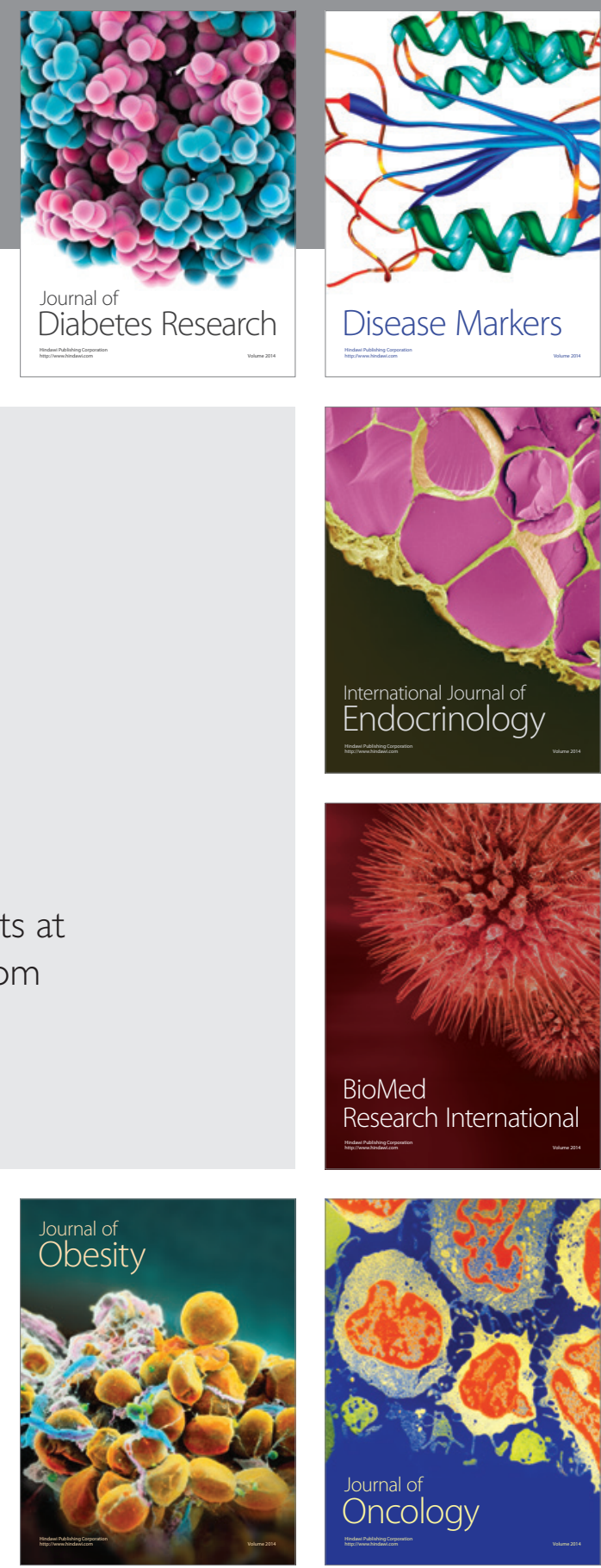

Disease Markers
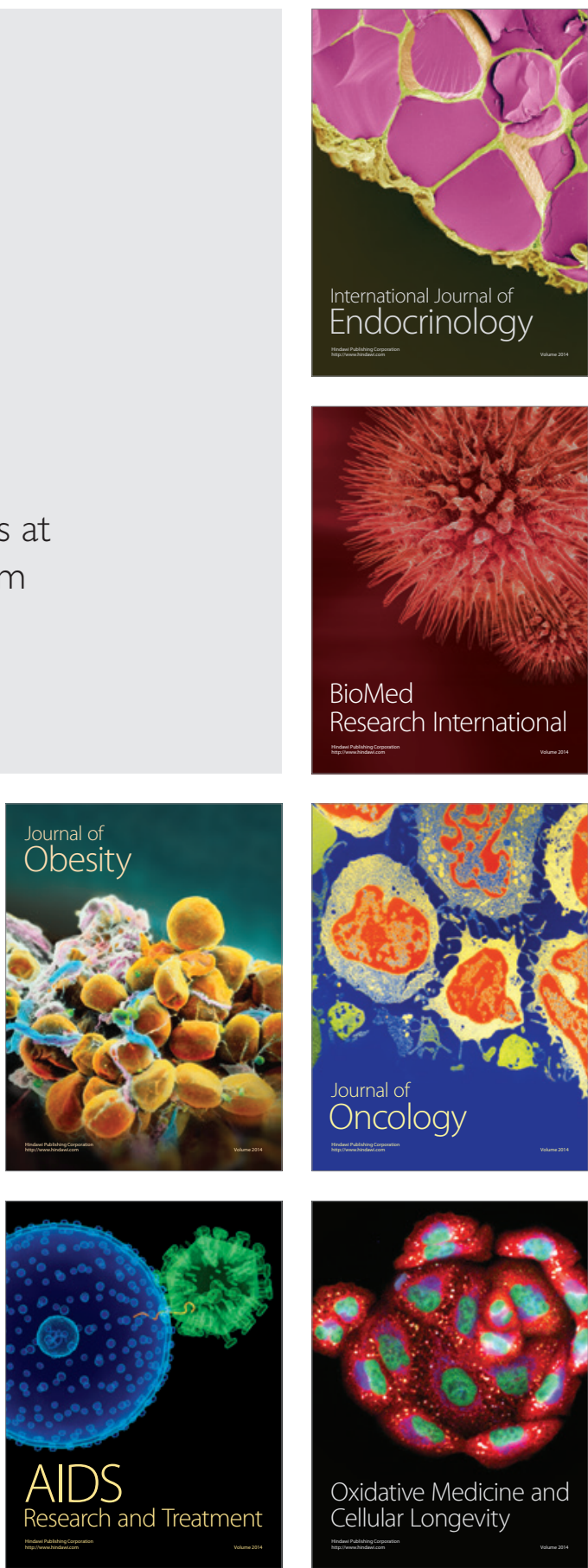